\title{
KARAKTERISTIK DAN IMPLEMENTASI TANAH LIAT DI LUBUK ALUNG SEBAGAI BAHAN BAKU PEMBUATAN KERAMIK HIAS
}

\author{
Taufik Akbar ${ }^{1}$, Wisnu Prastawa ${ }^{2}$ \\ ${ }^{1,2}$ Program Studi Seni Kriya Institut Seni Indonesia Padangpanjang \\ taufik723@gmail.com ${ }^{1}$, lempungart@yahoo.com²
}

\begin{abstract}
Clays as a raw material ceramics have a different characteristics. Characteristics of a clays take effect to quality and uniqueness a ceramics craft. This article is a result of craracteristic of clays in Lubuk Alung, District of Padang Pariaman and implemented to raw material of decorative ceramics. The purpose of research is development ceramics to find a new clay. The method of this research is action research and implemented the clay for decorative ceramic. Characteristic of clays of Lubuk Alung is earthenware clays, not quite plastic, the colour is terracotta, drying shrinkage of $10 \%$, firing shrinkage $11 \%$ $\left(800^{\circ} \mathrm{C}\right)$. The clays of Lubuk Alung combining with plastic clays from Sawahlunto to can be material of decorative ceramics (pottery).
\end{abstract}

Key Words: ceramics, material, clay characteristics, quality

\begin{abstract}
Abstrak: Tanah liat sebagai bahan baku keramk memiliki karakteristik berbeda-beda. Karakteristik suatu tanah liat berpengaruh pada kualitas sebuah karya keramik. Artikel ini adalah hasil penelitian karakteristik tanah liat di Lubuk Alung Kabupaten Padang Pariaman dan diimplementasikan menjadi bahan baku pembuatan keramik hias. Tujuan penelitian ini adalah untuk pengembangan kriya keramik. Penelitian ini menggunakan mentodologi penelitian tindakan serta mengimplementasikan tanah liat menjadi keramik hias. Tanah liat Lubuk Alung merupakan tanah jenis earthenware yang memiliki karakteristik kurang plastis, berwarna terakota dan memiliki perentase susut kering $10 \%$ serta susut bakar $11 \%$ $\left(800^{\circ} \mathrm{C}\right)$. Tanah liat Lubuk Alung dicampur dengan tanah liat plastis daerah Talawi Sawahlunto untuk dapat dijadikan bahan pembuatan keramik hias kategori tembikar.
\end{abstract}

Kata kunci: Karakteristik, Implementasi, Tanah liat, Lubuk Alung, Bahan baku, Keramik Hias

Tanah liat atau lempung dari dahulu sudah digunakan oleh sebagian masyarakat Indonesia sebagai bahan baku pembuatan benda-benda keramik. Benda keramik tersebut adalah berupa bata, periuk, tungku, jambangan, gentong hingga genteng .

Seiring perkembangan zaman pemanfaatan tanah liat mulai merambah pada pembuatan karya seni kriya di tengahtengah masyarakat. Karya tersebut berupa keramik hias baik berupa gerabah, maupun keramik bergelasir (Ponimin, 2018: 116). Oleh karena itulah kemudian berkembang beberapa sentra kerajinan keramik atau gerabah di Indonesia. Sentra kerajinan gerabah atau keramik di Indonesia secara tidak langsung tentu saja akan mengembangkan seni kriya dan juga menjadi sumber industry kreatif baru yang dapat meningkatkan ekonomi masyarakat.
Tumbuhnya seni keramik di Indonesia sendiri dapat dikatakan sebagi cabang yang masih baru, menurut Mochtar Kusuma Atmaja periode perkembangan tersebut dapat dibagi menjadi empat periode yaitu; Periode eksplorasi (sebelum 1960), Periode akademis (1963-1970), Periode pertumbuhan (1975-1985), Periode kemunculan perajin dan seniman (1985sekarang) (Prima Yustana, 2012).

Keberadaan sentra penghasil karya keramik tersebut tentu tidak lepas dari kualitas dan karakter tanah liat karya keramiknya. Kriya keramik merupakan salah satu cabang seni rupa yang menitik beratkan pada kualitas material (tanah liat) dan penguasaan keterampilan atau craftmanship dalam perwujudannya. Oleh karena itu untuk mendukung pengembangan 
kriya keramik dan gerabah selain keterampilan perlu penelitian dan kegiatan eksplorasi lebih banyak lagi terhadap tanah liat baru di berbagai daerah yang memiliki potensi tanah liat tersebut ( Ponimin, 2017: 249).

Tanah liat hampir dapat dijumpai di seluruh wilayah Indonesia dan pada dasarnya setiap tanah liat dapat dibuat menjadi gerabah. Di daerah Nagari Sikabu Kecamatan Lubuk Alung Kabupaten padang Pariaman terdapat tanah liat yang biasa disebut masyarakat setempat tanah klay yang berwarna merah dan berasal dari tebing bukit. Kata tanah klay merujuk pada bahasa Inggris tanah liat sendiri yaitu clay. Tanah ini biasa digunakan sebagai bahan pembuatan bata dan tanah inilah yang akan diteliti karakteristiknya dan diimplementasikan sebagai bahan utama keramik hias sebagi usaha untuk menemukan sumber bahan baku keramik/gerabah baru dan menarik minat masyarakat agar mau memanfaatkan tanah liat di daerah mereka menjadi kerajinan gerabah/keramik yang memiliki nilai ekonomis lebih tinggi daripada sebuah bata.

Penelitian tentang bahan baku gerabah/keramik masih sedikit dilakukan oleh seniman/kriyawan keramik. Padahal untuk mengembangkan kriya keramik dibutuhkan eksplorasi lebih banyak mengenai material tanah liat (Ponimin, 2018:114). Oleh karena itulah tujuan penelitian ini adalah untuk pengembangan kriya keramik, baik bagi kriyawan keramik dan masyarakat luas secara umum. Penelitian ini juga sebagai usaha untuk menemukan sumber bahan baku pembuatan keramik baru di Indonesia dan Sumatera Barat pada khususnya.

\section{METODE PENELITIAN}

Penelitian ini menggunakan metode experiment dengan menggunakan mentode pendekatan action research. Penelitian dilakukan dengan beberapa tahap dan langkah yang dilakukan secara runut. Penelitian Ini menggunakan metode kualitatif dengan membuat sampel karya sebagai salah satu hasil penelitian. Metode pengambilan sampling yang digunakan adalah purposive sample. Metode ini adalah cara mengambil sampel yang didasarkan pada tujuan tertentu, tujuan si peneliti dengan beberapa syarat (Arikunto,2002:117). Syarat-syarat yang harus dipenuhi tersebut adalah sebagai berikut:

1. Pengambilan sampel yang didasarkan pada sifat atau karakteristik tertentu yaitu ciri-ciri pokok populasi objek penelitian.

2. Sampel yang diambil adalah subjek yang paling dominan mengandung ciri-ciri yang ada pada populasi.

3. Penentuan karakteristik populasi dilakukan dengan cermat pada bagian pendahuluan.

Sampel yang diambil berupa tanah liat yang kemudian diolah dan dianalisa karakteristiknya melalui test piecest sederhana. Karakteristik tanah liat untuk dijadikan bahan baku utama keramik hias dianalisis berdasarkan plastisitas, warna, tekstur, susut kering dan susut bakar.

Tanah liat Lubuk Alung yang sudah diketahui karakteristiknya tersebut kemudian diimplementasikan sebagai bahan baku pembuatan keramik hias. Keramik hias yang dijadikan sampel diwujudkan dengan teknik putar dengan dekorasi underglass

Proses implementasi dan pembuatan sampel dilakukan dengan mempertimbangkan karakter tanah liat. Apabila karakter tanah liat Lubuk Alung ini kurang baik untuk dijadikan bahan baku tunggal, maka akan dicari komposisi yang tepat dengan mencampurnya dengan bahan bantu pembentuk keramik lainnya.

\section{HASIL PENELITIAN}

\section{A. Karakteristik Tanah Liat Lubuk Alung}

Jenis dan Warna Tanah Liat Lubuk Alung

Setiap tanah liat memiliki karakter dan sifatnya masing-masing. Tidak semua jenis tanah liat mampu dijadikan bahan baku gerabah /keramik dengan baik. Beberapa hal-hal yang mempengaruhi antara lain sifat 
plastisitas, sifat porous atau keporian, susut kering, susut basah dan kekuatan dari tanah liat tersebut. Meskipun demikian tanah liat dapat dimodifikasi untuk keperluan pembuatan karya keramik. (Gautama, 2011:19-20).

Tanah liat atau lempung Lubuk Alung diambil dari tebing bukit dengan kondisi yang masih mentah dan belum diolah, selanjutnya tanah tersebut diolah secara basah, disaring dan kemudian diuli menjadi tanah liat murni yang siap digunakan. Tanah liat daerah lubuk alung memiliki warna merah bata ketika dalam keadaan basah. Dari segi warna tanah liat ini dapat dikatakan termasuk ke dalam tanah liat jenis earthenware.

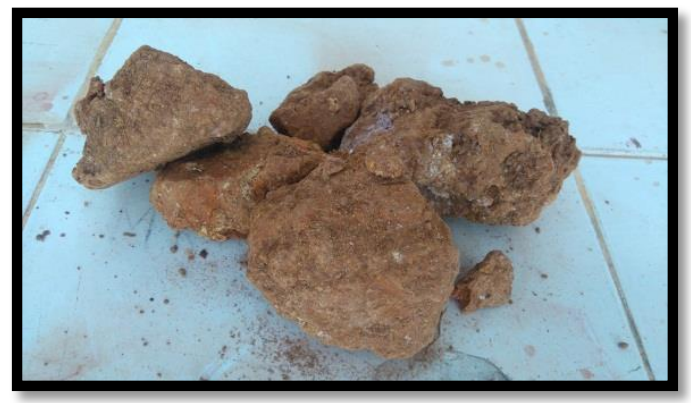

Gambar 1. Tanah liat Lubuk Alung mentah

Tanah liat jenis earthenware biasa digunakan sebagai bahan baku pembuatan bata, sedangkan dalam ilmu kriya keramik tanah jenis ini digunakan sebagai bahan baku pembuatan gerabah dan karya terakota lainnya. Gerabah pada dasarnya secara material masih tergolong benda keramik walaupun tidak melalui proses penggelasiran (Satrio, 2012: 172).

Tanah earthenware memiliki beberapa keunggulan dan kekurangan. Keunggulan yang dimilikinya adalah mudah ditemukan, sedangkan kekurangannya antara lain adalah adalah plastis, namun ada pula yang rapuh, selain itu tanah ini sulit dibakar bila tidak dicampur bahan lain dan suhu bakarnya yang kurang dari $1000^{\circ} \mathrm{C}$ $1100^{\circ} \mathrm{C}$ (Astuti, 2008: 8). Oleh karena itulah pada penelitian ini tanah Lubuk Alung akan dijadikan bahan baku keramik hias kategori gerabah/terrakota.

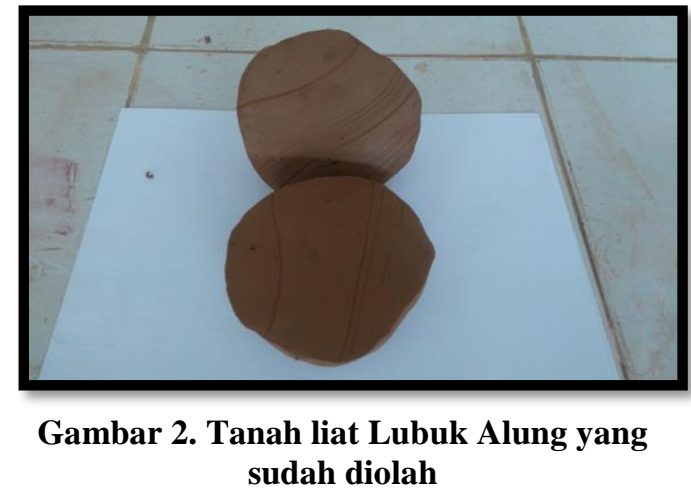

1. Plastisitas

Plastisitas adalah tingkat kelenturan dan kemudahan suatu tanah liat. Dalam kriya keramik tingkat plastisitas tanah liat sangat menentukan proses pembuatan. Tanah liat yang plastis akan lebih mudah dibentuk dibandingkan tanah liat yang kurang plastis. Menurut Ambar Astuti (2008: 5) sifat plastis dipengaruhi oleh partikel tanah, zat-zat organis yang membusuk dan bakteri.

Menguji plastisitas tanah liat dilakukan dengan test piecest melalui metode sederhana yaitu membentuknya menjadi cincin-cincin kecil. Apabila tedapat retakan pada bagian luar cincin tersebut atau bahkan patah berarti tanah liat tersebut kurang plastis.

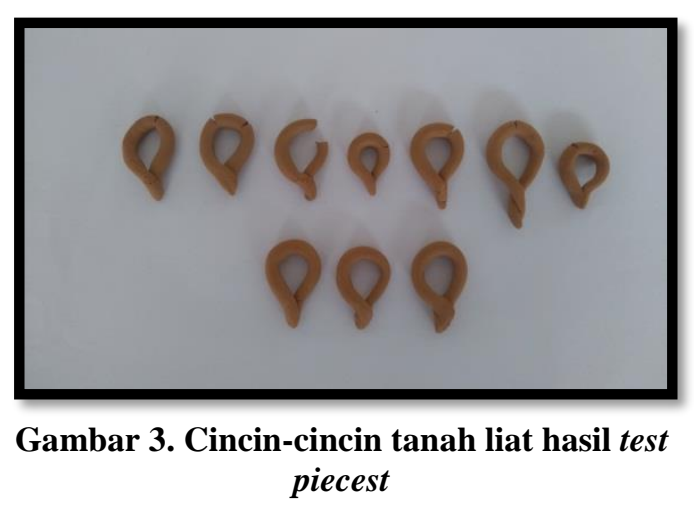

Tanah liat Lubuk Alung yang diuji plastisitasnya ternyata kurang plastis. Berdasarkan foto pada gambar 3 dapat diketahui bahwa terdapat banyak retakan pada sebagian besar cincin-cincin tanah litanya, bahkan beberapa ada yang patah sebelum dibakar. Dari sepuluh cincin lempung yang diuji ternyata tujuh 
diantaranya retak/tidak utuh. Dengan demikian maka untuk diimplementasikan menjadi karya keramik maka tanah ini dapat dicampur dengan tanah/bahan plastis lainnya (Ponimin, 2005: 72).

2. Susut Kering

Susut kering adalah persentase berkurangnya volume atau ukuran tanah liat setelah dibentuk. Proses penyusutan ini terjadi karena body tanah melepaskan kandungan air yang sebelumnya membuat tanah menjadi liat dan mudah dibentuk.

Menghitung persentase susut kering dilakukan dengan cara membuat lempenganlempengan tanah berukuran panjang $12 \mathrm{~cm}$, lebar $3 \mathrm{~cm}$ dan tebal $1,5 \mathrm{~cm}$. Lempengan tanah liat tersebut kemudian diberi garis tengah memanjang dengan ukuran $10 \mathrm{~cm}$. Garis tengah itulah yang diukur panjangnya setelah lempengan kering. Rumus menghitung persentase susut kering tanah liat adalah sebagai berikut:

Susut kering $=$ panjang basah-panjang kering $\times 100 \%$

$$
\text { panjang basah }
$$

$$
\frac{10 \mathrm{~cm}-9 \mathrm{~cm}}{10 \mathrm{~cm}} \times 100 \%=10 \%
$$

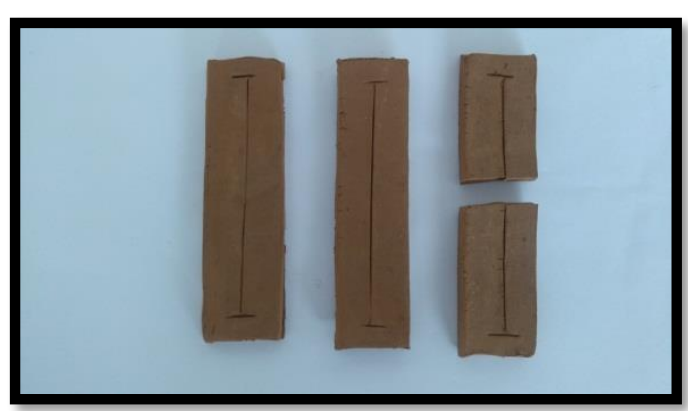

Gambar 4. Lempengan-lempengan untuk menguji susut kering

Tanah liat Lubuk Alung yang diteliti memiliki susut kering sebesar $10 \%$. Persentase ini cukup normal karena pada umumnya tanah liat memiliki persentase susut kering antara 5\%-12\%. Dari gambar 4 dapat diketahui bahwa tanah liat Lubuk Alung yang diuji susut keringnya ternyata ada yang patah dan sedikit melengkung.hal ini menunjukan bahwa selain kurang plastis body tanah liat ini juga lemah.

3. Susut bakar

Setiap tanah liat memiliki persentase susut bakar yang berbeda-beda. Proses pembakaran membuat volume dan ukuran tanah liat menjadi semakin berkurang karena melepasnya kadar air pada pembakaran. Pembakaran benda keramik secara umum dibagi pada dua tahap, yaitu pembakaran biskuit dan pembakaran gelasir. Pembakaran biscuit merupakan tahap pembakaran pertama dimana keramik dibakar pada suhu lebih kurang $\quad 800^{\circ}-1000^{\circ} \mathrm{C}, \quad$ sedangkan pembakaran gelasir adalah pembakaran yang dilakukan pada tahap penggelasiran dengan suhu yang lebih besar.

Tanah liat Lubuk Alung setelah dibakar biskuit memiliki persentase susut bakar sebesar $11 \%$. Persentase sebesar itu normal kaena pada umumnya susut bakar tanah liat bekisar antara 8-12\% (Astuti, 2008:23). Tanah liat ini hanya diuji dalam pembakarn biskuit karena untuk diimplementasikan menjadi keramik hias kategori gerabah memang sudah dapat dibakar pada proses pembakaran biskuit tanpa penggelasiran. Rumus menghitung susut bakar adalah sebagai berikut:

Susut bakar = panjang basah-panjang bakar $\mathrm{x} 100 \%$

panjang basah

$$
\frac{10 \mathrm{~cm}-8,9 \mathrm{~cm}}{10 \mathrm{~cm}} \times 100 \%=11 \%
$$

\section{B. Implementasi Tanah Liat Lubuk Alung sebagai Bahan Pembuatan keramik Hias}

Proses implementasi tanah liat Lubuk Alung sebagai bahan pembuatan keramik hias dilakukan dengan mewujudkan karya vas bunga yang dibentuk dengan teknik putar. Teknik ini dipilih karena memiliki resiko karya retak dan pecah yang rendah. Selain itu teknik putar juga lebih efektif dan efisien dalam pembuatan keramik khususnya karya-karya berjenis pottery atau tembikar. 
Tanah liat Lubuk Alung yang akan dijadikan keramik hias sebelumnya diolah kembali dengan menambahkan tanah liat plastis. Tanah liat plastis yang digunakan sebagai bahan campuran adalah tanah liat Talawi yang memiliki karakter yang sama namun lebih plastis. Persentase campuran tanah liat adalah 60\% (tanah liat Lubuk Alung berbanding 40\% (tanah liat Talawi), Tanah liat Talawi sendiri merupakan tanah liat dengan suhu bakar rendah berwarna merah dan memiliki persentase susut sebesar $12 \%$ Tanah liat ini juga masih berada di Sumatera Barat tepatnya di Kota Sawahlunto.

Karya keramik yang dibuat dibakar sebanyak dua kali yaitu proses pembakaran biskuit dan pembakaran gelasir. Pembakaran biskuit dibakar pada suhu $800^{\circ} \mathrm{C}$ dan pembakaran gelasir mencapai suhu $1070^{\circ} \mathrm{C}$.

Berikut ini adalah sampel karya dari tanah liat Lubuk Alung:

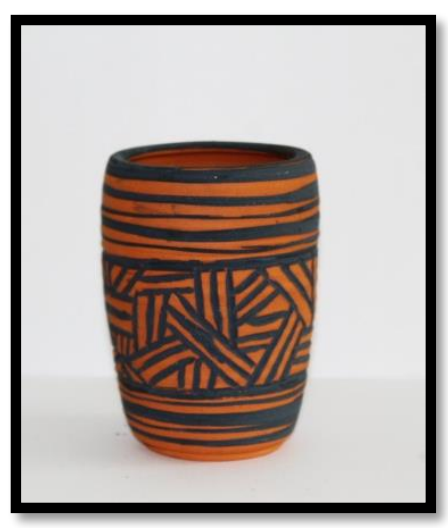

Gambar 5. Sampel karya keramik (vas bunga)

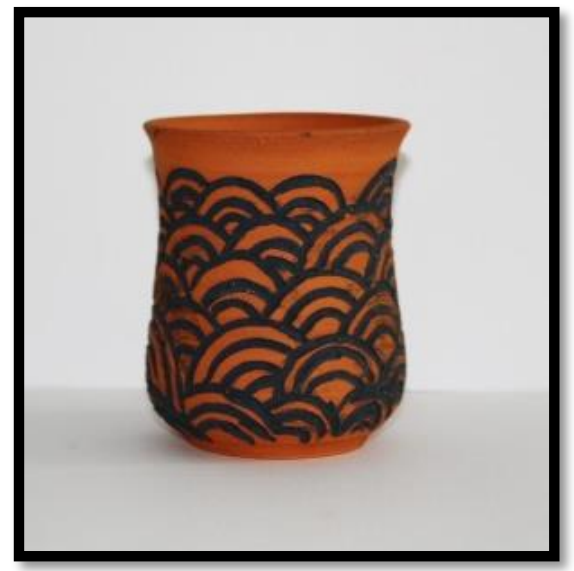

Gambar 6. Sampel karya keramik (vas bunga \#2)

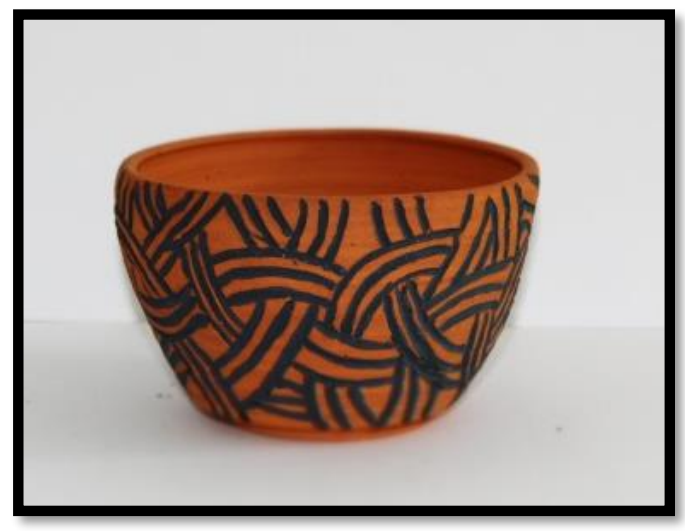

Gambar 7. Sampel karya keramik (vas bunga \#3)

Gambar 5-7 diatas merupakan hasil sampel karya berupa keramik hias yang sudah dibakar dan digelasir. Proses penggelasiran menggunakan teknik kuas dengan hasil gelasir doff. Semua sampel karya tidak mengalami retak dan pecah setelah dibakar.

\section{KESIMPULAN}

\section{A. Kesimpulan}

Berdasarkan penelitian yang dilakukan, dapat diambil kesimpulan sebagai berikut;

1. Tanah Liat Lubuk Alung termasuk jenis tanah earthenware.

2. Tanah Liat Lubuk Alung berwarna merah dengan karakter yang kurang plastis.

3. Tanah Liat lubuk Alung memiliki susut kering sebesar $10 \%$ dan susut bakar $12 \%$.

4. Tanah Liat Lubuk Alung dapat dicampur dengan tanah liat atau bahan plastis lainnya untuk dijadikan bahan baku keramik hias.

\section{B. Saran}

Saran dari penelitian ini adalah:

1. Tanah liat Lubuk Alung dapat diteliti untuk dimanfaatkan menjadi bahan baku pembuatan keramik hias dengan teknik lain seperti cetak, slab dan coil.

2. Penelitian tanah liat sebagai bahan baku keramik dapat dilakukan 
sesuai jenis keramik yang akan

\section{DAFTAR PUSTAKA}

Arikunto. (2002), Prosedur Penelitian: Suatu Pendekatan Praktik, Jakarta, Rineka Cipta.

Astuti, Ambar. (1997), Pengetahuan Keramik, Yogyakarta, Gadjah Mada University Press.

. (2008), Keramik: Bahan, Cara Pengerjann dan Gelasir, Yogyakarta, Arindo Nusa Media.

Gautama, Nia (2011), Keramik: Untuk Hobi dan Karir, Jakarta, Gramedia Pustaka Utama.

Ponimin, 2018, "Diversifikasi Desain Produk Sentra Keramik Dinoyo Bersumber Ide Budaya Lokal Malang, dalam Jurnal Bahasa Dan Seni, Tahun 46, Nomor 1, Februari 2018, pp: 111-122

(2017). "Revitalization of Traditional Jug Into Interior Aesthetic Element with "Glocal (Global Local) Culture" dalam ISOLEC Proceedings 2017, Faculty Of Letters, Universitas Negeri Malang, pp: 249-255.

, (2005). "Keramik Kasongan dalam Konteks perubahan Sosiokultural", Jurnal Bahasa Dan Seni, Tahun 33, Nomor 1, Februari 2005, pp: 70-82

Satrio, Adhi, Akbar. (2012), "Kriya Keramik: Wujud, Posisi dan Peranannya di Masa Kini dalam Jurnal Seni Kriya "Corak", 1/02, Jurusan Kriya Fakultas Seni Rupa ISI Yogyakarta, Yogyakarta

Yustana, Prima. (Mei-2012), "Karakteristik Tanah Liat dan Pengaruhnya terhadap keberhasilan Warna Gelasir dalam Jurnal Seni Kriya "Corak", I/01, Jurusan Kriya Fakultas Seni Rupa ISI Yogyakarta, Yogyakarta dibuat. 